\title{
Analisis Kualitas Layanan Pasien Jaminan Kesehatan Nasional (JKN) Mandiri di Instalasi Rawat Jalan Rumah Sakit Umum Daerah (RSUD) Sekayu Tahun 2019
}

\author{
Desi Ratnasari ${ }^{1}$, Misnaniarti², Yuanita Windusari $^{3}$ \\ 1,2,3Magister Program Studi Ilmu Kesehatan Masyarakat, Universitas Sriwijaya \\ ecispoofer@gmail.com ${ }^{1}$
}

ABSTRAK

Diajukan 31 Juli 2019 Diperbaiki 4 Mei 2020 Diterima 6 Mei 2020

Latar Belakang: RSUD Sekayu merupakan bagian dari fasilitas layanan kesehatan yang berkewajiban memberikan pelayanan berkualitas sesuai dengan harapan pasien. Penilaian IKM RSUD Sekayu saat ini belum spesifik menggambarkan kualiatas pelayanan dari sisi harapan dan kenyataan layanan pasien JKN Mandiri serta belum dapat memperlihatkan prioritas kategori pelayanan yang akan ditingkatkan/diperbaiki.

Tujuan: Menganalisis kualitas, terutama layanan rawat jalan berdasarkan 5 dimensi mutu pelayanan (service quality) terhadap peserta JKN Mandiri.

Metode: Metode yang digunakan yaitu cross sectional dengan 151 responden. Teknik pengumpulan data dengan kuesioner berskala likert. Data dianalisis berdasarkan Importance Performance Analiysis dan Gap Analysis.

Hasil: Rendahnya tingkat kepuasan pasien pada pelayanan Rawat Jalan $(47,7 \%)$ dengan tingkat kesesuaian rata-rata $76,89 \%$ dan gap rata-rata -1 . Pasien cenderung kurang puas terhadap pelayanan berorientasi pada proses (Reliability, Responsiveness, Assurance dan Empathy) dan cenderung puas pada dimensi yang berorientasi pada hasil (Tangible). Diagram kartesius memetakan 10 atribut pada kuadran A, 11 atribut pada kuadran B, 6 atribut pada kuadran C dan 10 atribut pada kuadran D.

Kesimpulan: Secara umum kualitas layanan pasien JKN Mandiri di RSUD Sekayu cukup baik pada dimensi Tangible, Responsivenes dan Assurance, sedangkan dimensi Empathy dan Reliability masih dinilai kurang. Perlu ada upaya perbaikan mutu layanan dari semua dimensi mengingat keterkaitan antara dimensi pelayanan.

Kata Kunci: kualitas pelayanan; jaminan kesehatan nasional; rawat jalan

\section{ABSTRACT}

Background: Sekayu Regional General Hospital as part of health service facilities is obliged to provide quality services in accordance with patient expectations. The assessment of satisfaction survey at Sekayu General Hospital has not yet described the quality of health services from expectations and the performance of JKN patients and has not shown the category of services prioritized for quality improvement

Objective: To analyze the quality especially in outpatient services of the Sekayu Regional Hospital based on 5 dimensions to the participants of the Mandiri National Health Insurance.

Methods: Used a cross sectional method with 151 respondents. Data collection techniques using a questionnaire with a Likert scale. Data were analyzed based on Importance Performance Analiysis and Gap Analysis.

Results: The results showed patient satisfaction with outpatient services at the Sekayu Public Hospital still low $(47.7 \%)$ an average level conformity of $76.89 \%$ and an average gap of -1.31 . Patients tend to be less satisfied with the process-oriented services (Reliability, Responsiveness, Assurance and Empathy) and tend to be satisfied in the results-oriented dimension (Tangible). The cartesius diagram maps 10 attributes in quadrant $A, 11$ attributes in quadrant $B, 6$ attributes in quadrant and 10 attributes in quadrant $D$

Conclusion: In general the quality of JKN patient services at Sekayu Hospital is quite good in the Tangible, Responsiveness and Assurance dimension, while Empathy and Reliability dimensions are still considered lacking. RSUD Sekayu should be improve the quality of services from all dimensions of quality because of the relationship between Its dimensions.

Keywords: quality of service; national health assurance (jkn); outpatient 
PENDAHULUAN

Salah satu program pemerintah yang dilaksanakan melalui mekanisme asuransi kesehatan sosial dimana kepesertaannya bersifat wajib yaitu Jaminan Kesehatan Nasional (JKN), yang dikelola oleh Badan Penyelenggara Jaminan Sosial Kesehatan (BPJS-Kesehatan). BPJS Kesehatan adalah badan hukum yang bertanggung jawab atas penyelenggaraan pelayanan kesehatan pada fasilitas kesehatan tingkat pertama dan tingkat lanjutan. Tujuan program ini adalah untuk menjamin peserta memperoleh manfaat pemeliharaan kesehatan dan perlindungan dalam memenuhi kebutuhan dasar kesehatan (Presiden RI, 2013).

Era JKN menuntut pemenuhan kualitas pelayanan dari suatu fasilitas kesehatan secara mutlak. Program ini menjanjikan hak yang sama atas akses, sumber daya di bidang kesehatan dan memperoleh pelayanan kesehatan yang aman, bermutu, serta terjangkau (Kemenkes RI, 2015). Kualitas (Quality) pelayanan adalah dasar dari pemasaran jasa bagi fasilitas kesehatan yang bergerak di bidang jasa dan tidak akan berjalan dengan baik tanpa adanya kualitas (Parasuraman et al., 1988).

Rawat jalan merupakan salah satu pelayanan yang diselenggarakan di rumah sakit, yang diumpamakan sebagai "pintu gerbang", sehingga kualitas pada rawat jalan akan sangat mempengaruhi keputusan pasien untuk tetap atau tidak memakai jasa pelayanan rumah sakit tersebut kembali. Jika pasien mendapatkan pelayanan yang prima, sesuai atau bahkan dapat melampaui harapan mereka, maka akan terbentuk sikap positif pasien terhadap pelayanan rawat jalan tersebut (Kusumapradja et al., 2013).

RSUD Sekayu tergolong fasilitas kesehatan tingkat lanjutan sesuai dengan kebijakan rujukan berjenjang program JKN, sehingga RSUD Sekayu menjadi rujukan bagi Fasilitas Kesehatan Tingkat Pertama (FKTP) di area Sekayu, termasuk 2 Rumah Sakit Kelas C yang ada di Kabupaten Musi Banyuasin. Selain itu, RSUD Sekayu juga menjadi RS Rujukan Regional yang mengampu 4 Kabupaten terdekat (Banyuasin, Pali, Musi Rawas dan Muratara), yang tentunya membuat tingkat kunjungan pada rawat jalan terus meningkat.

Adanya kerjasama yang dijalin RSUD Sekayu dengan BPJS Kesehatan, sudah sepatutnya menjadi kewajibkan RSUD Sekayu untuk memberikan pelayanan yang berkualitas/ bermutu, terutama kepada peserta JKN sebagai upaya mewujudkan suksesnya program JKN. Penilaian mutu layanan wajib dilakukan oleh tiap RS melalui penilaian kepuasan pelanggan. Selama ini, penilaian mengacu pada Indeks Kepuasan Masyarakat (IKM) Menpan RI Tahun 2004 yang dilakukan secara umum, baik pasien umum maupun JKN, di rawat jalan, rawat inap maupun IGD sehingga belum pernah ada penilaian mutu layanan khusus pasien JKN di RSUD Sekayu. Adanya nilai baik/ buruknya IKM yang diperoleh belum dapat menggambarkan pelayanan apa saja yang dinilai memenuhi ekspektasi atau harapan pasien. Adapun pelayanan yang berkualitas, yakni pelayanan yang mengacu pada preferensi, ekspektasi dan juga pada kebutuhan pasien (Zhao et al., 2009).

Penelitian ini bertujuan untuk menganalisis kualitas melalui penilaian harapan (ekspektasi) pasien dan kenyataan (kinerja) pelayanan yang diterima, mengacu pada dimensi service quality. Adapun data yang dipoleh selanjutnya dianalisa dengan motede Importance Performance Analysis (IPA) dan Gap Analysis yang diharapkan pada hasil akhir dapat menentukan prioritas perbaikan dalam meningkatkan kualitas/ mutu layanan yang diperlihatkan pada diagram kartesius. 
Analisis Kualitas Layanan Pasien Jaminan Kesehatan Nasional...

METODE

\section{A. Desain Penelitian}

Penelitian ini adalah penelitian deskriptif kuantitatif dengan metode cross sectional. Jumlah sampel yang diambil sebanyak 151 orang dengan menggunakan rumus lemeshow. Teknik pengambilan sampel dalam penelitian ini adalah non probability sampling yakni dengan accidental sampling. Sampel adalah pasien yang memperoleh pelayanan di Instalasi Rawat Jalan RSUD Sekayu dengan kriteria inklusi dan eksklusi. Data dikumpulkan dengan kuesioner berskala likert 1-5 melalui wawancara langsung kepada pasien. Sebelum disebarkan, instrumen (kuesioner) telah diuji validitas dan reliabilitas terhadap 30 responden. Analisis data yang digunakan adalah teknik analisis deskriptif berdasarkan Importance And Performance Analysis Methode (IPA) dan Gap Analysis.

B. Variabel dan Definisi Operasional

Variabel bebas pada penelitian ini adalah kualitas layanan pasien JKN Mandiri, dilihat dari perhitungan tingkat kesesuaian antara tingkat kenyataan pelayanan yang diterima dan tingkat harapan atau ekspektasi layanan berdasarkan dimensi servqual. Adapun variabel terikatnya adalah 5 dimensi kualitas pelayanan yaitu Tangibles (Bukti Fisik), Reliability (kehandalan), Responsiveness (ketanggapan), Assurance (jaminan) dan Empathy (empati).

\section{HASIL PENELITIAN}

\section{A. Karakteristik Responden}

Hasil penelitian didapat bahwa rentang umur pasien antara 17 s.d 77 tahun, sebagian besar responden berasal dari kelompok umur dewasa awal (26-35 tahun) sebanyak 64 orang $(42,4 \%)$, selanjutnya remaja akhir 19,9\%, dewasa akhir 16,6\%, lansia awal 10,6\%, lansia akhir 7,3\% dan manula 3,3\%. Responden berjenis kelamin perempuan sebesar 66,2\%. Pendidikan sebagian besar responden yakni Akademi/Perguruan
Tinggi sejumlah 87 orang $(57,6 \%)$, kemudian SLTA sejumlah 46 orang $(30,5 \%)$ sebagian kecil SMP dan tidak tamat/tamat SD. Pekerjaan sebagian besar responden yakni PNS/TNI/Polri 22.5\%, Karyawan Swasta 22.5\%, lain - lain 19.2\%, Wiraswasta $14.6 \%$, Ibu Rumah Tangga $13,9 \%$ dan sebagian kecil berstatus pensiunan, petani/buruh/pelajar/ mahasiswa dan belum bekerja.

Untuk lebih jelasnya Karakteristik Responden dapat dilihat pada Tabel 1 berikut ini.

Tabel. 1. Distribusi Frekuensi Karakteristik Responden

\begin{tabular}{|c|c|c|c|}
\hline No & Karakteristik & $\mathrm{n}$ & $\%$ \\
\hline \multirow[t]{7}{*}{1} & Usia (tahun) & & \\
\hline & Remaja Akhir (17-25 tahun) & 30 & 19.9 \\
\hline & Dewasa Awal (26-35 tahun) & 64 & 42.4 \\
\hline & Dewasa Akhir (36-45 tahun) & 25 & 16.6 \\
\hline & Lansia Awal (46-55 tahun) & 16 & 10.6 \\
\hline & Lansia Akhir (56-65 tahun) & 11 & 7.3 \\
\hline & Manula (lebih dari 65 tahun) & 5 & 3.3 \\
\hline \multirow[t]{3}{*}{2} & Jenis Kelamin & & \\
\hline & Laki-laki & 51 & 33.8 \\
\hline & Perempuan & 100 & 66.2 \\
\hline \multirow[t]{5}{*}{3} & Tingkat pendidikan & & \\
\hline & Tidak Tamat SD/Tamat SD & 9 & 6.0 \\
\hline & Tamat SMP & 9 & 6.0 \\
\hline & Tamat SLTA & 46 & 30.5 \\
\hline & Tamat PT (D1 s.d. S2) & 87 & 57.6 \\
\hline \multirow[t]{10}{*}{4} & Pekerjaan & & \\
\hline & PNS/TNI/POLRI & 34 & 22.5 \\
\hline & Pensiunan & 4 & 2.6 \\
\hline & Wiraswasta & 22 & 14.6 \\
\hline & Karyawan Swasta & 34 & 22.5 \\
\hline & Petani/Buruh & 2 & 1.3 \\
\hline & Pelajar/Mahasiswa & 3 & 2.0 \\
\hline & Ibu Rumah Tangga & 21 & 13.9 \\
\hline & Belum Bekerja & 2 & 1.3 \\
\hline & Lain-lain & 29 & 19.2 \\
\hline \multirow[t]{3}{*}{5} & Penghasilan/Pendapatan & & \\
\hline & Kurang dari UMR & 75 & 49.7 \\
\hline & Lebih dari sama dengan UMR & 76 & 50.3 \\
\hline \multirow[t]{5}{*}{6} & Kelas Kepesertaan BPJS & & \\
\hline & Kelas 3 & 24 & 15.9 \\
\hline & Kelas 2 & 66 & 43.7 \\
\hline & Kelas 1 & 61 & 40.4 \\
\hline & Total & 151 & 100 \\
\hline
\end{tabular}

B. Analisis IPA

Setelah skor harapan dan skor kenyataan pelayanan yang diterima 
responden peserta JKN yang dikhususkan untuk pasien Non PBI, dilakukan analisis kesesuaian antara harapan dan kenyataan menggunakan analisis IPA yaitu perbandingan rata-rata skor kenyataan pelayanan yang diterima dibandingkan harapan atas layanan yang dinginkan.

Hasil perbandingan tingkat kesesuaian antara harapan dan kenyataan pelayanan pasien JKN Mandiri di rawat jalan, diperoleh rata-rata kesesuaian keseluruhan (gabungan 5 dimensi) yaitu $76,89 \%$ yang dijadikan cut off point. Apabila dilihat dari setiap dimensi yang mempunyai persentase kesesuaian rendah, kinerjanya dinilai belum mampu memenuhi keinginan pasien, sehingga pasien kurang puas pada pelayanan dimensi tersebut. Berdasarkan urutannya, dimensi Tangible (79,93\%), Responsivenes $(78,15 \%)$, Assurance $(77,34 \%)$ berada diatas rata-rata, sehingga bisa dikategorikan dapat memenuhi harapan responden terhadap pelayanan sedangkan dimensi Empathy (76,26\%) dan Reliability (72,81\%) memiliki kesesuain yang rendah sehingga belum memenuhi harapan responden terhadap pelayanan. Secara jelas digambarkan pada gambar 1 .

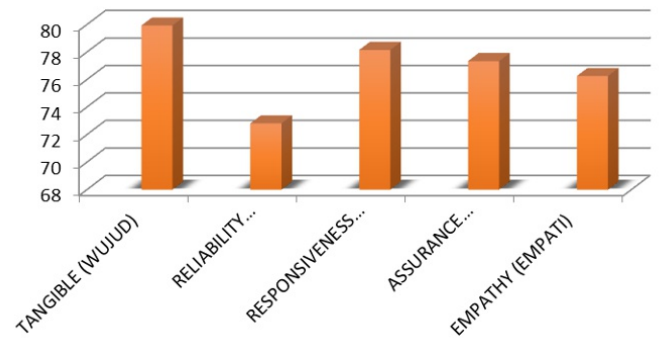

Gambar 1. Kesesuaian Harapan dan Kenyataan pelayanan

C. Distribusi Frekuensi Kepuasan Pasien

Hasil perhitungan distribusi frekuensi kepuasan pasien terhadap layanan dilihat dari tingkat kesesuaian harapan dan kenyataan pelayanan dari setiap responden di rawat jalan RSUD Sekayu, untuk melihat gambaran kepuasan perdimensi yaitu dengan cut off point nilai rata-rata masing-masing variabel dimensi sedangkan untuk melihat kualitas pelayanan keseluruhan berdasarkan cut off point dari nilai rata - rata IPA keseluruhan.

Didapatkan hasil bahwa sebagian besar pasien puas terhadap pelayanan pada dimensi Tangible sebesar 54.3\%, namun pasien kurang puas pada pelayanan dimensi Reliability sebesar $54.3 \%$, pada dimensi Responsiveness sebesar 53\%, pada dimensi Assurance sebesar $57 \%$ dan pada dimensi Empathy sebesar 58,3\%. Bila dilihat secara keseluruhan, hanya $47,7 \%$ pasien yang puas dan sebagian besar (52,3\%) kurang puas dengan pelayanan rawat jalan RSUD Sekayu, hasil ditampilkan pada tabel 2.

Table 2. Dimensi Mutu Kepuasan Pasien

\begin{tabular}{|c|c|c|c|}
\hline $\mathrm{No}$ & Dimensi Mutu & $\mathrm{n}$ & $(\%)$ \\
\hline \multirow[t]{3}{*}{1} & Tangible & & \\
\hline & Kurang puas & 69 & 45.7 \\
\hline & Puas & 92 & 54.3 \\
\hline \multirow[t]{3}{*}{2} & Reliability & & \\
\hline & Kurang puas & 82 & 54.3 \\
\hline & Puas & 69 & 45.7 \\
\hline \multirow[t]{3}{*}{3} & Responsiveness & & \\
\hline & Kurang puas & 80 & 53 \\
\hline & Puas & 71 & 47 \\
\hline \multirow[t]{3}{*}{4} & Assurance & & \\
\hline & Kurang puas & 86 & 57 \\
\hline & Puas & 65 & 43 \\
\hline \multirow[t]{5}{*}{5} & Empathy & & \\
\hline & Kurang puas & 88 & 58.3 \\
\hline & Puas & 63 & 41.7 \\
\hline & Total & 151 & 100 \\
\hline & $\begin{array}{l}\text { Kualitas Pelayanan } \\
\text { Keseluruhan }\end{array}$ & & \\
\hline 1 & Kurang puas & 79 & 52.3 \\
\hline \multirow[t]{2}{*}{2} & Puas & 72 & 47.7 \\
\hline & Total & 151 & 100 \\
\hline
\end{tabular}

D. Gap Analysis

Data perhitungan kesenjangan (gap) menunjukkan semua nilai atribut/kriteria penilaian mendapatkan nilai negatif, ratarata melebihi -1 (rata-rata total -1,31), hasil perhitungan kesenjangan perdimensi yaitu dimensi Tangible $(-1,14)$, Responsivenes (-1,27), Assurance (-1,32) lebih kecil dari gap rata-rata sedangkan gap dimensi Empathy $(-1,38)$ dan Reliability $(-1,54)$ lebih besar dari rata-rata. Dari hasil perhitugan gap menandakan kualitas 
Analisis Kualitas Layanan Pasien Jaminan Kesehatan Nasional...

pelayanan yang diberikan kurang baik dan belum dapat memberikan kepuasan kepada pasien. Menurut Parasuran (1988), jika gap yang dihasilkan <-1 artinya baik, dan jika hasilnya $>-1$ artinya kualitas pelayanan yang diberikan belum baik (Parasuraman et al., 1988).

E. Diagram Kartesius

Analisis menggunakan diagram kartesius untuk menentukan upaya dalam meningkatkan kualitas layanan terutama untuk layanan JKN di Instalasi Rawat Jalan RSUD Sekayu. Dalam pembuatannya, pertama-tama tentukan nilai sumbu $X$ serta sumbu $Y$ sebagai titik potong untuk membagi bidang menjadi 4 kuardran seperti digambarkan pada gambar 2.

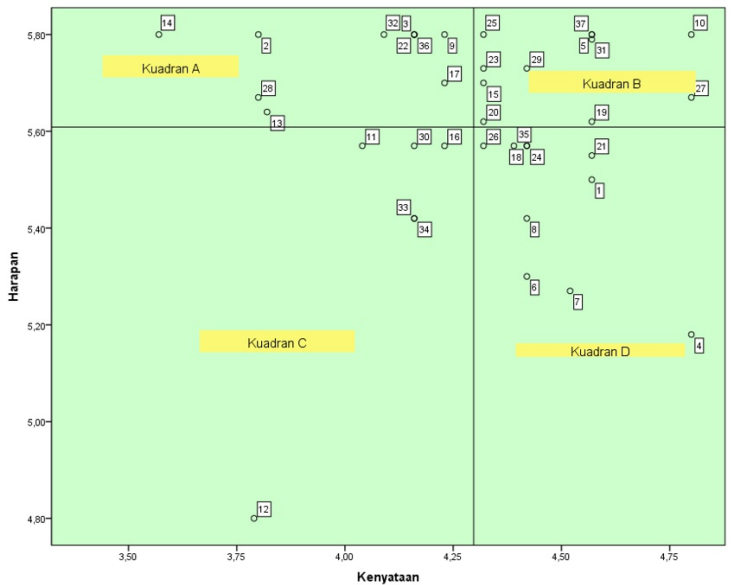

Gambar 2. Kesesuaian Harapan dan Kenyataan pelayanan

Diagram kartesius memetakan 10 atribut pada kuadran A, diantaranya waktu tunggu pelayanan obat, ruang tunggu obat, keramahan dan kesopanan perawat, pelayanan yang tidak dibedabedakan, kesabaran dan perhatian perawat, respon dan ketanggapan petugas pendaftaran, kebersihan toilet, kelengkapan alat kesehatan, dan kejelasan persyaratan administrasi. Adapun 11 atribut pada kuadran B diantaranya yaitu, kemampuan petugas farmasi dalam memberi penjelasan, respon cepat petugas farmasi, pelayanan oleh tenaga yang berkompeten, kemampuan perawat dalam membantu dokter memberikan penjelasan, keramahan dan kesabaran petugas farmasi, penampilan perawat, dokter memberikan informasi penyakit dengan jelas, kebersihan alat yang digunakan dan keramahan dokter. Pada kuadran $\mathrm{C}$ terdapat 6 atribut diantaranya yaitu, kehadiran dokter tepat waktu, keamanan dalam mendapatkan pelayanan, prosedur sederhana, kesabaran dan perhatian petugas pendaftaran, kemudahan menyampaikan masukan kepada pihak RS, singkatnya waktu penyiapan dokumen rawat jalan. Pada kuadran D terdapat 10 atribut, diantaranya keramahan petugas pendaftaran, kesabaran dokter, kesigapan dokter dan perawat, kejelasan informasi dari petugas pendaftaran, sarana prasarana pelayanan yang lengkap, kesediaan tenaga medis (dokter serta perawat) menjawab pertanyaan pasien, kondisi ruang pemeriksaan baik, penampilan dokter petugas farmasi dan petugas pendaftaran).

\section{PEMBAHASAN}

\section{A. Analisis Kepuasan Pasien JKN Mandiri} Terhadap Pelayanan

Seberapa jauh rumah sakit dapat memberikan pelayanan sesuai dengan harapan pasien, dapat dilihat dari kepuasan yang diperlihatkan oleh pasien atas pelayanan yang diterimanya. Kepuasan pelanggan adalah pelayanan yang dipilih oleh pelanggan minimal sama atau melampaui harapannya sedangkan mutu layanan dikategorikan kurang baik dan belum dapat memuaskan pelanggan apabila pelayanan yang pasien terima lebih rendah dari harapannya. Dapat diketahui kunci utama memuaskan pelanggan salah satunya adalah dengan memahami dan mengelola ekspektasi (harapan) pelanggan (Tjiptono, 1996).

Berdasarkan hasil perhitungan kepuasan dengan menghitung kesesuain kenyataan pelayanan yang diterima dengan harapan responden menggunakan cut off point, yang digunakan dari persentase nilai rata-rata IPA keseluruhan 
(76,89\%), menunjukkan sebagian besar responden $(52,3 \%)$ kurang puas dengan pelayanan rawat jalan dan hanya $47,7 \%$ pasien yang puas terhadap pelayanan rawat jalan RSUD Sekayu. Hasil perhitungan kepuasan ini masih cukup jauh dari Standar Pelayanan Minimal yang ditetapkan oleh Kemenkes RI, yaitu nilai kepuasan pelayanan untuk rawat jalan diangka $\geq 90 \%$ (Menteri Kesehatan RI, 2008). Didukung dengan data perhitungan kesenjangan (gap), nilai atribut/kriteria penilaian mendapatkan nilai negatif dan rata-rata melebihi -1 artinya kualitas pelayanan yang diberikan masih kurang baik dan belum dapat memberikan kepuasan kepada pasien.

Dilihat dari kepuasan responden perdimensi, dari lima dimensi hanya pada dimensi tangible sebagian besar responden $(54,3 \%)$ puas terhadap pelayanan yang diberikan sedangkan berdasarkan dimensi lain sebagain besar responden kurang puas yaitu pada Reliability sebesar 54.3\%, dimensi Responsiveness sebesar 53\%, dimensi Assurance sebesar $57 \%$ dan dimensi Empathy sebesar 58,3\%. Dari 5 dimensi mutu menurut Parasuraman, yang termasuk pada jenis ukur yang berorientasi pada hasil adalah Tangible dan yang berorientasi pada proses adalah Reliability, Responsiveness, Assurance dan Empathy. Jika dilihat dari hasil perhitungan, responden cenderung kurang puas terhadap dimensi yang berorientasi pada proses. Adapun Ratminto dan Atik (2005) mengatakan penilaian yang baik haruslah terdiri dari 2 jenis ukuran yaitu berorientasi pada proses dan pada hasil (Ratminto dan Winarsih, 2005), artinya masih banyak atribut/kriteria penilaian yang harus diperbaiki terutama pada dimensi yang berorientasi pada proses.

Dilihat dari segi aturan, RSUD Sekayu sudah memiliki aturan yang baik, dengan memiliki akreditasi paripuna, artinya dokumen-dokumen penting seperti kebijakan, pedoman, petunjuk teknis juga Standar Operasional Prosedur (SPO) dalam pelayanan sudah dimiliki, peneliti menyarankan untuk peneliti selanjutnya melihat budaya pelayanan yang ada di RSUD Sekayu, apakah sudah memahami pelayanan prima atau belum, serta apakah sudah memahami SPO/ aturan yang ada dan indikator kepuasan pasien, terutama pada pegawai yang terlibat langsung dengan pasien.

B. Analisis Tingkat Kesesuaian dan Kesenjangan Layanan Perdimensi

Zeithaml et al. (1990) mengatakan bahwa harapan pelanggan mempunyai peranan penting dalam penilaian kepuasan pasien karena harapan adalah keyakinan pelanggan sebelum mendapatkan pelayanan kesehatan, sehingga dijadikan sebagai acuan atau standar dalam menilai kinerja dari pelayanan kesehatan. Maka dengan mengidentifikasi dan memahami atribut pelayanan yang paling diharapkan pasien, fasilitas kesehatan bisa melakukan upaya perbaikan untuk meningkatkan kualitas pelayanan pada atribut yang pelaksanaanya dinilai kurang namun harapannya tinggi (Zeithaml et al., 1990).

Dilihat berdasarkan kesesuaian keseluruhan yaitu 37 atribut/kriteria penilaian, terdapat $18(49,6 \%)$ atribut/ kriteria penilaian dari penilaian yang mempunyai nilai kesesuaian $\geq 76,89 \%$ dan masih ada 19 (51,4\%) atribut/kriteria penilaian yang tingkat kesesuainnya rendah dan harus ditangani dengan menentukan prioritas perbaikan berdasarkan diagram kartesius. Bila dilihat dari nilai gap harapan dan kenyataan per item, rata-rata atribut/ kriteria penilaian mendapat nilai negatif dan melebihi -1 (- 1,31) dan hanya 6 atribut yang memiliki nilai minus dibawah -1 sedangkan untuk kesenjangan tertinggi yang mencapai -2 terdapat 2 atribut. Dari analisis gap, dapat digambarkan bahwa kualitas pelayanan di RSUD Sekayu masih rendah karena menurut Parasuran (1988), jika gap yang 
dihasilkan $<-1$ artinya baik dan bila hasil $>-1$ artinya kualitas pelayanan yang diberikan kurang baik.

Pada Dimensi Tangible ada 3 atribut yang masih memiliki nilai gap yang cukup besar yaitu ruang tunggu RS yang kurang nyaman, toilet yang kurang bersih, dan RS memiliki alat kesehatan yang kurang lengkap. Tidak hanya di RSUD Sekayu, permasalahan kelengkapan alkes memang menjadi masalah utama, seperti yang disimpulkan dalam penelitian sebelumnya di puskesmas Kota Depok, bahwa aspek atribut struktur pelayanan yang dinilai pelanggan perlu perbaikan adalah kelengkapan sarana (Ayubi, 2009). Pada penelitian Wicaksono et al. (2014) ditemukan permasalahan pada kebersihan toilet dikarenakan pihak ketiga yang menangani kebersihan menjalankan audit hanya untuk formalitas saja (Wicaksono et al., 2014). Sebaiknya, sebagai RS milik pemerintah dengan penampilan gedung yang cukup megah haruslah memiliki fasilitas toilet umum yang baik agar dapat meningkatkan kenyamanan pasien.

Pada Dimensi Reliability juga terdapat 3 atribut yang mempunyai kesesuaian rendah dan gap yang cukup besar sehingga termasuk sebagai prioritas perbaikan, diantaranya persyaratan administrasi pelayanan yang kurang jelas dan kurang mudah dipahami, waktu tunggu pelayanan rawat jalan dan waktu tunggu pelayanan obat. Permasalahan pada waktu tunggu juga memang menjadi masalah utama pada puskesmas di Kota Depok yaitu waktu tunggu pendaftaran yang harus segera dibenahi (Ayubi, 2009). Penelitian Borie (2013), Ratih (2010) dan Alwy (2018) menunjukkan adanya hubungan antara keandalan dan kepuasan pasien (Al-Borie dan Damanhouri, 2013; Alwy, 2018; Hardiyati dan Khasanah, 2010), sehingga dimensi ini menjadi dimensi utama yang harus diperbaiki, dengan sebagian besar atribut-atribut pelayanan yang prioritas diperbaiki.
Pada dimensi Responsiveness atribut petugas pendaftaran merespon secara cepat dan tanggap menjadi masalah yang menjadi prioritas perbaikan karena pada penelitian Borie dan Damanhouri (2013) dan Alwy (2018) menunjukkan adanya hubungan antara daya tanggap dan kepuasan pasien (Al-Borie dan Damanhouri, 2013; Alwy, 2018).

Pada dimensi Assurance atribut perawat ramah dan sopan dalam melayanai pasien menjadi prioritas perbaikan sehingga RS belum dapat dapat dikategorikan meyakinkan pasien, seperti yang disampaikan Supriyanto (2010) bahwa RS dapat menimbulkan rasa percaya dan yakin akan jaminan kesembuhan pasien dengan menyampaikan pelayanan yang disertai rasa hormat dan sopan (Supriyanto dan Ernawaty, 2010).

Pada dimensi Empathy atribut memberikan pelayanan tanpa membedabedakan dan perawat melayani dengan sabar dan penuh perhatian, RS perlu memperbaiki atribut ini agar kepuasan pasien dari segi empati dapat meningkat, sesuai dengan penelitian Alwy bahwa ada hubungan antara empati dengan kepuasan (Alwy, 2018).

Bila dilihat dari persentase kesesuaian perdimensi, 3 dimensi memiliki persentase rata-rata kesesuaian yang lebih dari nilai rata-rata keseluruhan, yaitu Tangible (79,93\%), Responsivenes (78,15\%), Assurance (77,34\%), namun ada 2 dimensi yaitu dimensi Empathy (76,26\%) dan Realiability $(72,81 \%)$ persentase rataratanya rendah. Kelima dimensi ini saling berkaitan sehingga perbaikan harus dilakukan dari setiap dimensi terutama pada atribut/kriteria penilaian yang mempunyai kesesuaian yang rendah dan nilai gap yang besar.

Penjelasan Parasuraman sebelumnya menjelaskan bahwa seluruh dimensi kualitas jasa dalam SERVQUAL memiliki interaksi satu sama lain, sehingga dalam upaya peningkatan 
kualitas tidak bisa dipisahkan antara dimensi satu dengan yang lain agar kepuasan pasien terhadap pelayanan dapat lebih baik, bukan hanya puas pada dimensi tertentu. Sebagian besar atribut/ kriteria penilaian yang diprioritaskan untuk diperbaiki berasal dari dimensi pelayanan yang berorientasi pada proses, artinya pelayanan dari staf kepada pasien sedangkan untuk dimensi yang berorientasi pada hasil yaitu Tangible sudah mendapatkan kesesuaian yang baik, dimana dimensi ini mendapatkan nilai kesesuaian yang paling tinggi dan gap paling rendah dari dimensi yang lain dan sebagian besar pasien puas terhadap dimensi ini, walaupun tetap ada atribut pada dimensi ini yang harus diperbaiki kualitasnya.

\section{PENUTUP}

Rendahnya kepuasan pasien $(47,7 \%)$ pada pelayanan rawat jalan, dari hasil analisis data dengan tingkat kesesuaian rata-rata yakni sebesar $76,89 \%$ dan gap rata-rata $-1,31$. Pasien cenderung kurang puas terhadap pelayanan yang orientasinya pada proses, yaitu Reliability, Responsiveness, Assurance dan Empathy serta cenderung puas pada dimensi yang berorientasi pada hasil (Tangible). Diagram kartesius memetakan 10 atribut pada kuadran A, 11 atribut pada kuadran B, 6 atribut pada kuadran $C$ dan 10 atribut pada kuadran D.

Secara umum kualitas layanan pasien Jaminan Kesehatan Nasional Mandiri di RSUD Sekayu cukup baik pada dimensi Tangible, Responsivenes dan Assurance, sedangkan dimensi Empathy dan Reliability masih dinilai kurang. Perlu ada upaya perbaikan mutu layanan dari semua dimensi kualitas karena adanya hubungan antar dimensi yang saling berkaitan untuk meningkatkan kualitas pelayanan yang baik kepada pasien JKN, diantaranya:

a. Dimensi Tangible: membuat ruang tunggu obat lebih nyaman, yaitu dengan disediakan pendingin ruangan dan dilengkapi TV, meningkatkan kebersihan toilet dan monitoring pekerjaan oleh pihak ketiga, menganggarkan alat kesehatan sesuai kebutuhan ruangan

b. Dimensi Reliability: waktu tunggu dipersingkat agar SPM pelayanan rawat jalan tercapai yaitu dengan mencari akar masalah bersama komite farmasi dan terapi, waktu tunggu layanan di rawat jalan dipersingkat sesuai SPM dengan mendisiplikan kehadiran dokter, mempermudah prosedur administrasi dengan partisipasi tim Humas.

c. Dimensi Responsiveness: mempercepat pelayanan pendaftaran, menganalisa kecukupan jumlah SDM diposisi tersebut agar respon petugas bisa cepat dan waktu penyediaan dokumen cepat.

d. Dimensi Assurance: memperbaiki keramahan dan kesopanan perawat dengan pelatihan etika pelayanan (service excellent), penerapan kembali program senyum sumpit dan $5 S$.

e. Dimensi Empathy: tidak membedabedakan pelayanan dengan meningkatkan partisipasi tim Humas dalam memberikan sosialisasi yang menyadarkan petugas terhadap prinsip dan standar layanan. Kemampuan komunikasi efektif petugas perlu ditingkatkan melalui pelatihan. Tim Humas mengaktifkan kembali kotak saran / media penyampaian saran, melakukan evaluasi berkala, serta membuat dan melaporkan rencana tindaklanjut dan penyelesaian.

RS Sekayu merupakan RS pemerintah yang mendapatkan dana anggaran untuk operasional kegiatan RS dan juga merupakan Badan Layanan Umum Daerah (BLUD) yang mengelola sendiri pendapatannya sehingga dana untuk perbaikan dapat diusahakan segera. 
DAFTAR PUSTAKA

Al-Borie, H. M., dan Damanhouri, A. M. S. (2013). Patients' Satisfaction of Service Quality in Saudi Hospitals: A SERVQUAL Analysis. International Journal of Health Care Quality Assurance, 26(1), 20-30. https://doi.org/ $10.1108 / 09526861311288613$

Alwy, S. N. A. (2018). Analisis Kepuasan Pasien Rawat Inap di Rumah Sakit Pemerintah (RSUD Haji Makassar) [Universitas Hasanuddin]. http:// digilib.unhas.ac.id/uploaded_files/ temporary/DigitalCollection/ OTNhZDVmNjI1ZGIzOGUzMzczMz U0ZjYwNzgyOWU2NWI0YzE4NTM $5 \mathrm{MA}==. \mathrm{pdf}$

Ayubi, D. (2009). Penilaian Kualitas Pelayanan Puskesmas dengan Model Donabedian: Studi Kasus Puskesmas di Kota Depok. Kesmas: National Public Health Journal, 4(1), 24. https://doi.org/ 10.21109/kesmas.v4i1.197

Hardiyati, R., \& Khasanah, I. (2010). Analisis Pengaruh Kualitas Pelayanan Terhadap Kepuasan Konsumen Menggunakan Jasa Penginapan (Villa) Agrowisata Kebun Teh Pagilaran [Universitas Diponegoro]. http:// eprints.undip.ac.id/23450/

Kemenkes RI. (2015). Universal Health Coverage. Mediakom Kementrian Kesehatan RI. http:// mediakom.sehatnegeriku.com/ universal-health-coverage

Kusumapradja, R., Suandewi, N. P. A., \& Germas, A. (2013). Analisis Hubungan Antara Kualitas Pelayanan, Karakteristik Pasien, Dan Hambatan Pindah Loyalitas Pasien Rawat Jalan RSUD Cibinong. Forum Ilmiah Jurnal Bunga Rampai, 10(1). https://ejurnal.esaunggul.ac.id/ index.php/Formil/article/view/824

Keputusan Menteri Kesehatan RI Nomor 828 Tahun 2008 Tentang Petunjuk Teknis Standar Pelayanan Minimal Bidang Kesehatan Di Kabupaten/ Kota, Pub. L. No. 828/MENKES/SK/IX/
2008 (2008).

Parasuraman, A., Zeithaml, V. A., \& Berry, L. L. (1988). Servqual: A MultipleItem Scale for Measuring Consumer Perceptions of Service Quality. Journal of Retailing, 64(1), 12-37. https:// www.researchgate.net/profile/ Valarie_Zeithaml/publication/ 225083802_SERVQUAL_A_multiple_Item_Scale_for_measuring_consume r_perceptions_of_service_quality/ links/5429a4540cf27e39fa8e6531/ SERVQUAL-A-multiple-Item-Scalefor-measuring-consumer-percepti

Peraturan Presiden Republik Indonesia Nomor 12 Tahun 2013 Tentang Jaminan Kesehatan, Pub. L. No. No. 12 Tahun 2013 (2013).

Ratminto, \& Winarsih, A. S. (2005). Manajemen Pelayanan. Pustaka Pelajar.

Supriyanto, S., \& Ernawaty. (2010). Pemasaran Industri Jasa Kesehatan. Andi Publisher.

Tjiptono, F. (1996). Manajemen Jasa. Andi Yogyakarta.

Wicaksono, B., Setyanto, N. W., \& Oktavianty, O. (2014). Analisis Kepuasan Pelanggan Pada Pelayanan Kesehatan Dengan Menggunakan Metode Potential Gain in Customer Value (Pgcv) Dan Entropy (Studi Kasus: Rumah Sakit Mardi Waluyo Kota Blitar). Jurnal Rekayasa Dan Manajemen Sistem Industri, 2(3). http:// jrmsi.studentjournal.ub.ac.id/ index.php/jrmsi/article/view/114

Zeithaml, V. A., Parasuraman, A. P., \& Berry, L. L. (1990). Delivering quality service: balancing customer perceptions and expectations. London: Free Press. https://cmc.marmot.org/

Record/.b11405181

Zhao, S. H., Akkadechanunt, T., \& Xue, X. L. (2009). Quality nursing care as perceived by nurses and patients in a Chinese hospital. Journal of Clinical Nursing, 18(12), 1722-1728. https:// doi.org/10.1111/j.13652702.2008.02315.x 